5. Kang DH, Park SJ, Rim JH, Yun SC, Kim DH, Song JM, et al. Early surgery versus conventional treatment in asymptomatic very severe aortic stenosis. Circulation. 2010;121:1502-9.

6. Bohbot Y, Pasquet A, Rusinaru D, Delabre J, Delpierre Q, Altes A, et al. Asymptomatic severe aortic stenosis with preserved ejection fraction: early surgery versus conservative management. J Am Coll Cardiol. 2018;72:2938-9.

7. Campo J, Tsoris A, Kruse J, Karim A, Andrei AC, Liu M, et al. Prognosis of severe asymptomatic aortic stenosis with and without surgery. Ann Thorac Surg. 2019;108:74-9.

8. Taniguchi T, Morimoto T, Shiomi H, Ando K, Kanamori N, Murata K, et al. Initial surgical versus conservative strategies in patients with asymptomatic severe aortic stenosis. J Am Coll Cardiol. 2015;66:2827-38.

9. Kim HJ, Kim JB, Kim HR, Ju MH, Kang DY, Lee SA, et al. Impact of valve replacement on long-term survival in asymptomatic patients with severe aortic stenosis. Am J Cardiol. 2019;123:1321-8.

10. Miura S, Yamashita T, Hanyu M, Kumamaru H, Shirai S, Ando K. Propensity score-matched analysis of patients with severe aortic stenosis undergoing surgical aortic valve replacement. Open Heart. 2019;6:e00992.
11. Kaleschke G, Baumgartner H. Asymptomatic aortic stenosis: when to operate? Curr Cardiol Rep. 2011:13:220-5.

12. Rosenhek R, Binder T, Porenta G, Lang I, Christ G, Schemper M, et al. Predictors of outcome in severe, asymptomatic aortic stenosis. N Engl J Med. 2000;343: 611-7.

13. Jalava MP, Laakso T, Virtanen M, Niemalä M, Ahvenvaara T, Tauriainen T, et al. Transcatheter and surgical aortic valve replacement in patients with recent acute heart failure. Ann Thorac Surg. 2020;109:110-7.

14. Brown ML, Pellikka PA, Schaff HV, Scott CG, Mullany CJ, Sundt TM, et al. The benefits of early valve replacement in asymptomatic patients with severe aortic stenosis. J Thorac Cardiovasc Surg. 2008;135:308-15.

15. Pellikka PA, Nishimura RA, Bailey KR, Tajic AJ. The natural history of adults with symptomatic, hemodynamically significant aortic stenosis. J Am Coll Cardiol. 1990; 15:1012-7.

16. Banovic M, Iung B, Bartunek J, Asanin M, Beleslin B, Biocina B, et al. Rationale and design of the aortic valve replacement versus conservative treatment in asymptomatic severe aortic stenosis (AVATAR trial): a randomized multicenter controlled event-driven trial. Am Heart J. 2016;174:147-53.
See Article page 1778.

\section{Commentary: Early surgery versus conservative management of asymptomatic severe aortic stenosis: Is it time to rethink the guidelines?}

\section{Oliver J. Liakopoulos, MD}

The debate about the optimal management of asymptomatic severe aortic stenosis (AS) is ongoing. Current European and US guidelines recommend surgical aortic valve replacement (SAVR) or transcatheter aortic valve replacement only in symptomatic patients with severe AS (class I). ${ }^{1,2}$ In the absence of symptoms and severe AS, only SAVR is currently indicated in the presence of an impaired left ventricular dysfunction (left ventricular ejection fraction $<50 \%$; class I) or abnormal exercise test

From the Department of Cardiac Surgery, Kerckhoff Clinic, Campus Kerckhoff, University of Gießen, Bad Nauheim, Germany.

Disclosures: The author reported no conflicts of interest.

The Journal policy requires editors and reviewers to disclose conflicts of interest and to decline handling or reviewing manuscripts for which they may have a conflict of interest. The editors and reviewers of this article have no conflicts of interest.

Received for publication Aug 16, 2020; revisions received Aug 16, 2020; accepted for publication Aug 17, 2020; available ahead of print Aug 20, 2020.

Address for reprints: Oliver J. Liakopoulos, MD, Department of Cardiac Surgery, Kerckhoff Clinic, Campus Kerckhoff, University of Gießen, Benekestr. 2-8, 61231 Bad Nauheim, Germany (E-mail: o.liakopoulos@kerckhoff-klinik.de).

J Thorac Cardiovasc Surg 2022;163:1788-9

$0022-5223 / \$ 36.00$

Copyright $(92020$ by The American Association for Thoracic Surgery

http://dx.doi.org/10.1016/j.jtcvs.2020.08.047
Check for updates

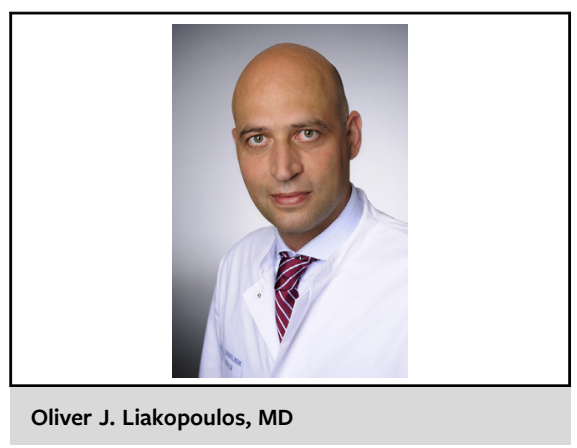

CENTRAL MESSAGE

This systematic review with meta-analysis demonstrates the benefit of early surgery for asymptomatic patients with severe AS in terms of reduced all-cause and cardiovascular mortality.

result (class I). If none of these 2 criteria are fulfilled, SAVR is downgraded to a class IIa recommendation mainly for asymptomatic patients with very severe AS.

Current evidence is scarce with only a few observational studies showing improved survival with early aortic valve replacement in asymptomatic patients with AS compared to watchful waiting. ${ }^{3-5}$ However, important evidence was recently provided by the results of the multicentric RECOVERY trial that randomly assigned in a 1:1 ratio 
145 patients with asymptomatic, very severe AS to early surgery or conservative care. ${ }^{6}$ The primary composite end point of 30-day mortality or death from cardiovascular causes during the 4-year follow-up period was significantly reduced in the intention-to-treat analysis in favor of the early surgery group ( $1 \%$ vs $15 \%)$. This translated into a number needed to treat of 20 patients to prevent 1 death within the 4-year follow-up. Early surgery was also linked to a lower incidence of death from any cause in the RECOVERY trial, thereby underscoring the fact that risk factors such as progressive myocardial damage or sudden cardiac death might contribute to the impaired outcome of asymptomatic patients during the watchful waiting period.

In this issue of the Journal, Yokohama and co-workers ${ }^{7}$ aimed to further strengthen the evidence for or against an early SAVR strategy in patients with asymptomatic AS. The authors systematically reviewed the results from 1 randomized controlled trial (RCT), 3 propensity score-matched trials, and 7 observational trials reporting a total of 2240 patients with asymptomatic severe or very severe AS. Early surgery versus conservative treatment was performed in 1007 and 1233 patients, respectively. Pooled analysis showed a significant benefit for the early surgery compared with the conservative strategy for both the primary effect measure (all-cause mortality; hazard ratio, $0.49 ; 95 \%$ confidence interval, 0.36-0.68; $P<.0001$ ) and secondary effect measure (cardiovascular mortality; hazard ratio, $0.42 ; 95 \%$ confidence interval, $0.22-0.82 ; P<.01$ ). The superiority of an early SAVR strategy in terms of a reduced all-cause mortality persisted even after subgroup analysis including only studies reporting adjusted outcome data or patients with severe or very severe AS.

At first glance, the results of the present systematic review are clear and impressive. The authors can be congratulated for summarizing the currently available evidence on this important topic. In addition, the data of this systematic review confirm the excellent surgical midterm survival previously reported by Kang and colleagues ${ }^{6}$ in asymptomatic patients with severe AS. Finally, the results of this meta-analysis closely reflect existing data from the few observational studies and clearly underscore the survival benefit of an early SAVR strategy when directly compared with the conservative watchful wait strategy in this specific patient cohort. ${ }^{3-5}$ Although this metaanalysis is certainly limited by the low number of included trials, and especially RCTs, it represents an important step toward filling the existing gaps of evidence with respect to the benefit of early elective surgery in asymptomatic severe AS. However, the exact criteria for identifying the optimal timing for early surgery are still largely unclear, and reliable evidence from RCTs is urgently needed to provide the optimal treatment strategy for these patients.

\section{References}

1. Baumgartner H, Falk V, Bax JJ, De Bonis M, Hamm C, Holm PJ, et al. 2017 ESC EACTS guidelines for the management of valvular heart disease. Eur Heart $J$. 2017;38:2739-91

2. Nishimura RA, Otto CM, Bonow RO, Carabello BA, Erwin JP III, Guyton RA, et al. 2014 AHA/ACC guideline for the management of patients with valvular heart disease: executive summary: a report of the American College of Cardiology/American Heart Association task force on practice guidelines [published correction appears in J Am Coll Cardiol. 2014;63:2489]. J Am Coll Cardiol. 2014:63:2438-88

3. Taniguchi T, Morimoto T, Shiomi H, Ando K, Kanamori N, Murata K, et al. Initial surgical versus conservative strategies in patients with asymptomatic 280 severe aortic stenosis. J Am Coll Cardiol. 2015;66:2827-38

4. Campo J, Tsoris A, Kruse J, Karim A, Andrei A-C, Liu M, et al. Prognosis of severe asymptomatic aortic stenosis with and without surgery. Ann Thorac Surg. 2019;108:74-9.

5. Miyake M, Izumi C, Taniguchi T, Morimoto T, Amano M, Nishimura S, et al Early surgery vs. surgery after watchful waiting for asymptomatic severe aortic stenosis. Circ J. 2018;82:2663-71.

6. Kang DH, Park SJ, Lee SA, Lee S, Kim DH, Kim HK, et al. Early surgery or conservative care for asymptomatic aortic stenosis. N Engl J Med. 2020;382:111-9.

7. Yokohama Y, Takagi H, Kuno T. Early surgery versus conservative management of asymptomatic severe aortic stenosis: a meta-analysis. J Thorac Cardiovasc Surg. 2022;163:1778-85.e5. 